\title{
On the Formal Connotation of Residential Door Decoration under the Influence of Shanxi Merchants'Culture
}

\author{
Xiaojie $\mathrm{Hu}$ \\ Huanggang Normal College \\ Huanggang, China
}

\begin{abstract}
Shanxi door decoration is architectural decoration of Shanxi mountain people created under the profound influence of regional environment and business culture. It shows a plain and friendly artistic style. Based on Qiao family courtyard, Wang family courtyard, Ding village and other Shanxi merchant' dwellings of particular features, the paper makes investigation and analysis, to research the overall grand layout concept of Shanxi dwelling door decoration, the plain and frank veins decoration, carvings of unified technique and other form characteristics, and to deliberate the connotative relation with the culture of Shanxi merchant.
\end{abstract}

Keywords - door decoration; culture of shanxi merchants; door decoration

\section{INTRODUCTION}

Residential door decoration is the integrative object of the folk custom and art. With the rise and fall of the Shanxi merchants, Shanxi residential door decoration has a long-term history evolution, and until today, it still is unique among many residential door decorations in China, having great attraction to many people. The success of Shanxi people is not inseparable from their diligence as well as their enterprising and cooperative spirit. They changed the idea of "good scholar will made good official' into that of "good scholar will make good merchant". They introduced the Confucian education of honesty, righteousness, faithfulness and forgiveness into the commercial society, gradually achieved a cultural merchant group, which has been regarded as a virtue in Shanxi from generation to generation. The uprightness, honesty, industriousness of Shanxi people has created a simple aesthetics of Shanxi people. Shanxi door decoration was the creature affected by this simple aesthetics and it reflects the Shanxi merchants' characteristics.

\section{CASE ANALYSIS ON THE RESIDENTIAL HISTORIC VILLAGE DOOR DECORATIONS OF SHANXI MERCHANT COURTYARD}

In order to research Shanxi door decoration form and connotation, we focus on the center of Shanxi, south of Shanxi, and southeast of Shanxi, beginning from the rich Shanxi merchant courtyard (Qiao family courtyard, Wang Family Courtyard and Wang courtyard), and residential historic village (Ding village), to make analysis on the local door decoration and its connotation.

\section{A. The "Vase" Door Decoration of the Qiao Family Courtyard and the Life Concept of the Integrity and Harmony}

Qiao family courtyard is located in the present Qi County, Shanxi, was built during the reign of Emperor Qianlong s, until the early years of the republic of China, was restructured for many times, although the time was spanning two centuries, it still keeps the totally natural architectural style, and is an ancient house having Northern Han Chinese traditional localstyle dwelling houses style. The consistency of the architectural decoration in those years seems very rare.

The literature and art of the Ming and Qing dynasties led the rapid development of the arts, and the builders of Qiao family courtyard, who are well informed and diligent in thinking, have the life experience of travelling the various places around the world, and they integrated the strong wish to posterity into the details of construction. As shown in "Fig. 1": animal head appliqués are made of wood or iron, anaglyph method obviously adopts the printmaking technique of Ming and Qing dynasties, looking delicate and unique. It is special for veins, and also has a unique style on materials and technique of expression. There are dozens of door decoration in the courtyard, and all the animal head appliques are vases, with a similar body but different details. As shown in "Fig. 1", the vase body is thin or plump and the bottleneck is thick or thin; most bottoms have base seat, with the vase body and seat are in plan view and the vase mouth in top view. At the bottleneck, door rings are hung, likewise at foot or body of vase, two ear-like things are arranged, and sometimes at the lower part of vase body, embossment is arranged as the decoration. The partial tone of the Chinese character “瓶” (vase) is the same as the pronunciation of Chinese character "平" (safety), and so many vases in so characteristic modes and so exquisite door decoration in technique, fully witness the host's wishing for the family safe in the future.

This article is the key project of Hubei province department of education in 2015: Door art decoration research (project number: 15D122) and 2014 Huanggang normal college scientific research project: Research on auspicious emblazonry of the decorative door (project number: 2014014703). 


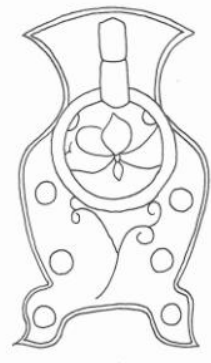

1

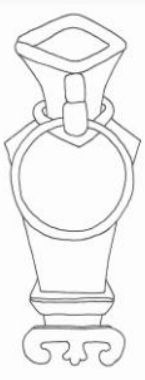

2
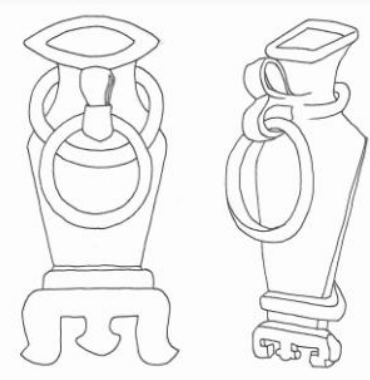

3 doornails on harmoniously.

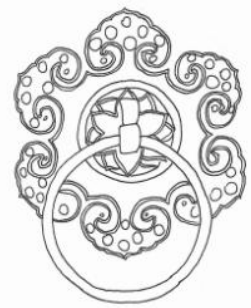

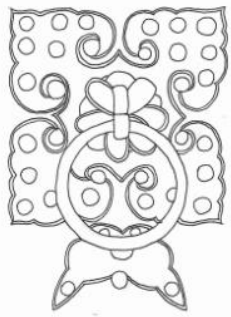

2

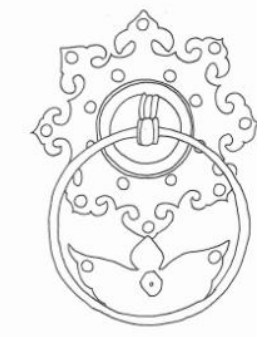

3
The signboard expresses the family precept of "People should do thing in accordance with the heavenly principles, and the behavior in the life and the spiritual sustenance should follow the ancient sages", and "generous and magnanimous people must have a happy family that will gets merciful, peaceful and prosperous", and "the only secret of family prospering is diligent and virtuous quality; the best way of conducting self in society is to keep forthright and sincere" which all reflect the concept of Qiao family for keeping generous, kind and honest, and pursuing a harmonious life.

Wang Family Courtyard's Door Decoration Shows the Culture of Shanxi Merchants of "Good" and "Giving".

The location of Wang family courtyard now is belonging to Jinzhong area, which was built in Ming and Qing Dynasties and completed through more than 300 years. The construction scale is large with rich and exquisite decoration; indeed, it was an architectural art museum of Han nationality. "Selfexamination like the reflection of the mirror, cultivating morality like growing tree, and nourishing soul like fish farming", this is a famous couplet at Wang family courtyard. The meaning is that all is derived from the correct path, motivating, and inspiring Wang family offspring work hard and keep integrity.

Once the merchant behavior is listed into the category of home culture, the whole wisdom can rise. Engaging in trade not only brings Wang family with fortune accumulation, but also benefits their open field of vision and broad mind. With "good" and "giving" as the principle of home construction, Wang's innovation and development, virtually brings the courtyard with more implication, the courtyard is magnificent in the overall planning, absorbing the excellent style of the south garden in details, integrating the courtyard skills and gardening art systemically, and becomes the exquisite building in Shanxi.

As shown in "Fig. 2", the door decoration of Wang family courtyard maintains the overall characteristic of Shanxi door decoration, and additionally the process of the door decoration is concentrated to the elegant artistic characteristics, and influenced by Hui-style, at the center of single animal head applique is the hemisphere added, in small size but appearing stereo consciousness. On the top of the hemispheroid, there is flowers decoration, with rich and artistic arrangement The door decorations still take the raised mastoid nail as the major element, in regular array, reflecting each other with the
Fig. 2. Some door decorations of Wang family courtyard

\section{B. "Nai Type Sword" of Ding Village and Life Pursut of Home-guarding and Exorcising}

Ding village is under the jurisdiction of Linfen, Shanxi now; there are 40 residential houses of Ming and Qing dynasties. The earlier was built in the $21^{\text {st }}-40^{\text {th }}$ year of Wanli period of Ming Dynasty, and the later was built in KangxiXianfeng period of Qing Dynasty. The "Nail type sword", named by author, refers to all the sword style decorations, which is based with iron sheet, top-arranged with raised mastoid nails. As shown in "Fig. 3", as the representative of residential houses in the south of Shanxi Province, the nail type sword of the Ding village is down inserted longitudinally along the crack of the door, one for each crack, and when closing the door, the two are integrated into one, then the sword scabbard is formed, which is downward standing at the center of the door, maybe in the purpose of the Ding village people to remove the evil. The modeling of "nail type swords" is different, which is based on the doornails arrangement density and the height and thickness of doornails, for example, No. 22 Courtyard has ten horizontal swords and two vertical swords, the No. 1 Courtyard of Ding village folklore museum has four horizontal swords and two vertical swords, of which each horizontal row has seven nails, the No. 39 Courtyard has four horizontals swords and two vertical swords, of which the horizontal is thin and the vertical is thick; and the No. 23 Courtyard has five horizontal swords and two vertical swords, of which each horizontal row has five big nails and each longitudinal row has small nails. These "nail type swords" have different shapes, and the scabbards are different in length and width. Such as No. 39 Courtyard and No. 22 Courtyard as shown in "Fig. 3", the joint of sword handle and scabbard appears round, and others are mostly square. 


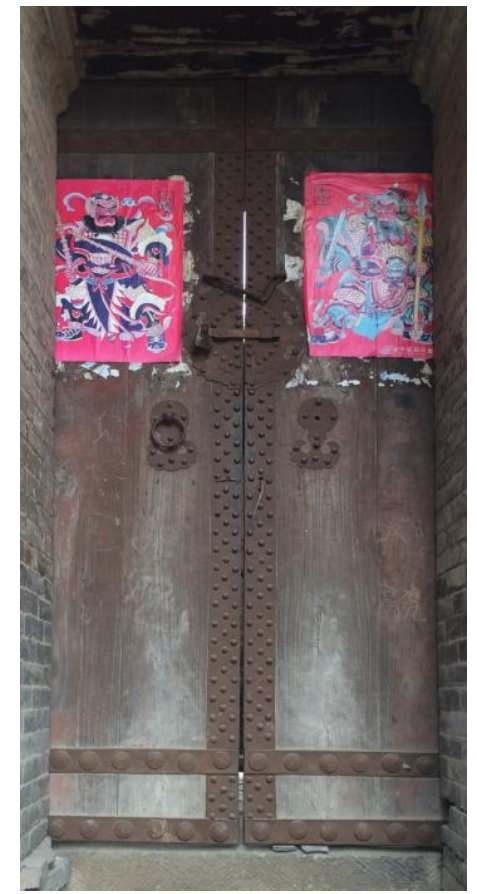

Fig. 3. The "Nail type sword" of Ding village

The differences in modeling also express in the door decoration. The forms of the door decoration are extremely rich. There are treasured vase, Buddha's-hand, animal heads and etc., and the door decorations of the non-important family are mostly square, such as No. 39 courtyard: the door decoration is a small foot vase, and No. 22 courtyard: the door decoration is the Buddha's-hand, and one the back of the hand, there are many small dot decorations, with very exquisite cuff design; No. 23 courtyard: the door decoration is hexagonal, and the surface has line-carved decorative pattern, and the head is cube. The doornail under the knocker is the phoenix style. The animal head applique of No. 1 courtyard of museum is a dog head ring, and there is a dog head at the top place of the door cymbal, and under the door rings are the two large doornails with the decorative pattern of small bat, which are used for knocking door; At the top and bottom of the door, the four decorative patterns of literal are used, liking the two Chinese characters of “山西 (Shanxi)" in the preliminary observation, and the decorative effect of all lucky patterns is rich and full.

The "nail type sword" on the gate is regarded as the things to repel evil spirits and avert misfortune, and according to the various suspicious decorative patterns used in the Ding village, we can feel the Ding village people has strongly pursuit of life. This is the original intention of the people to build the house.

The success of Shanxi merchants is inseparable with the influence of Confucian culture. They generalized the virtues of thrift, honest and trustworthy quality from the traditional culture, and brought the harmonious concept into the business practice, played the power of the group. As the house they built, they are modest and plain, maximally mobilized the manpower to create the grand and beautiful houses. The utmost efforts of the Shanxi merchants on the housing construction greatly improve the level of the local craftsman, and also create a large number of outstanding vernacular architecture heritages.

\section{THE FORM FEATURES AND CONNOTATION OF SHANXI RESIDENTIAL DOOR DECORATION}

\section{A. The Concept of the Overall Grand Layout of the Shanxi Door Decoration under the Culture of Shanxi Merchants}

In the nationwide investigation, the decorations on the door plank mostly are animal head applique. The application of such a large number of door nails and such a large figure arranged with door nails on the door plank is rare. The emergence of "nail type sword" is an important symbol of Shanxi door decoration different from the door decorations in the south. On the one hand, the overall layout on door plank by the Shanxi people is inseparable with the culture of Shanxi merchants. The ambition of the Shanxi merchants, "wide heart embraces all" created the whole magnificent momentum; On the other hand, from the regional characteristics, Shanxi was not far from the capital of China in that time, was more affected by the consciousness of the capital architecture decoration. For example, the second door of Ding village No. 22 courtyard, has the door horizontal board with the inscription of "Yi House", and more than eight hundred door nails are inlaid in the door plank, which are arranged as the patterns of "group longevity", "incense burner", "Svastika", "treasured vast" and others, and this is one of the most gorgeous door decorations, meaning blessing, longevity and luck, peace and safe.

Door nails earliest are used to strengthen the door plank, and in order to avoid wood board scattered, a belt is added on the door, and then doornail are used to reinforce, which is based on the practical function; latter, the door nails are made more and more beautifully, then the soak nails formed and more and more orderly arranged. In Sui and Tang dynasties (581-907), it was applied in the front door. Later, the feudal ruling class endowed it with ritual consciousness and thought. The number and size of nails more and more imply the social level. Till the Qing Dynasty, the color of the door, the number and the size of nails, are defined in the "Collection Statutes in the Qing Dynasty".

From the investigation of three places, the door nails in the door decoration are used mostly in Ding village, partly in Wang family courtyard partially, hardly in Qiao family courtyard. Combined with the construction time, Ding village was established in the early Wanli period of Ming dynasty, in that time, the regulations on doornails have not yet introduced, so Ding village still retains more nail type door decorations; Wang family courtyard built in the 300 years of Ming and Qing dynasties, partial doornails are reserved, but in the middle and late period of the Qing dynasty, the Qiao family courtyard directly avoided the use of door nails.

\section{B. The Plain and Frank Pattern of Shanxi Door Decoration under the Agricultural Civilization}

The narrow sense of the door decoration can be understood as the combination of doornail and animal head applique. The 
sword-pattern door decoration is common in Jinzhong and Linfen areas. The sword is composed of the door mails horizontally and vertically arranged, and the forms are slightly different. I consider that the sword is the thing of stabilizing home and avoiding evil spirits. The Shanxi people making the sword down inserted in the door, is most probably to take it as the talisman, hoping the home door can resist the evils and blessing their family.

As an integral part of door decoration, the patterns of bat, flowers and plants, and animal head commonly used in the other regions are also the elements of Shanxi door decoration, and additionally many patterns of characters, vases, copper coins, Ruyi, fish and etc are used for Shanxi door decoration, with a straightforward form expression, reflecting the influence of Confucianism on the honest and plain character of Shanxi people.

Particularly worth mentioning is that in the investigation of southeastern Shanxi door decoration, I found that there are large number of hollowed copper coins decoration. It is unavoidable that the businessmen chase the fortune. There were many hollowed adornments of auspicious words such as "blessing", "fortune ", "longevity" and "厉", which very intuitively show the good wishes of Shanxi people for future life. The meaning of "禄" (fortune) has two kinds of expression technique, one is a direct word, and the other is patterns of deer, "福" is the same, one directly using the pattern of “福” (blessing) and the other using the image of bat instead. In Gaoping, Jincheng and other places, two patterns combined are used more frequently in door decoration. "福" (blessing) and "寿"(longevity) are used together to express the "both happiness and longevity"; the "兽 "(animal) is homophonic with "寿" (longevity), so the pattern of Ruyi with animal head means "a long life as you whish", and if the pattern of bat is combined, it means "rich and worshipful as you wish" and "blessing and longevity as you wish".

As shown in "Fig. 4", in the door decoration of the southeast Shanxi, there is a particular thing, called "base plate" in the Lou Qingxi's "Beauty of Thousands of Doors", absent in other regions. The base plate is a metal slice of protecting door, originally used to reduce the damage of the door from door cymbal, but it apparently has become an important part of the door decoration in this area and its decoration is welldefined. The independent auspicious character words, or door god, or fish, or peach, or deer is used with extremely rich content, and keep harmony and unity with the door decoration in the technique.
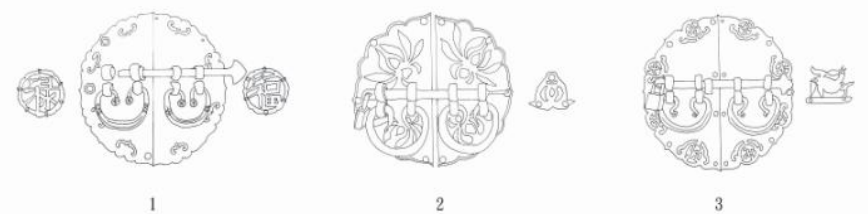

Fig. 4. Door decorations of Southeast Shanxi

\section{The Carving Craft of Unified Shanxi Door Decoration Technique under the Regional Characteristics}

Shanxi has vast territory and abundant resources, with rich iron content, so the iron sheet is selected for the material of door decoration in Shanxi. The rich residents directly use the iron sheet for bezel setting and then make decoration. Except the doornails mentioned for many times, the plane modality of holistic impression is emphasized for the door decoration, with very clear craft style and the unified technique of single line engraving and openwork carving. As shown in Fig. 4, the door decoration in the southeast Shanxi adopts hollowed pattern of “福” and “禄”, lotus, “与㝍” and a large number of lucky patterns, with plain and cordial artistic carving. And some door decorations adopt line carving of gate god and peach, with a crass and generous image, free from conventions, but they have elegant and exquisite style in the viewpoint of northern folk house. The consistency of carvings makes the decorative style of the Shanxi merchant residence house get an intangible unity.

If comparing with the door decorations of south merchant group in the same period, you can find that the decoration styles in the north and in the south are very different. The main decorations of Hui style mainly depend on the animal head applique. They lay emphasis on the stereo sensation for each animal head appliqué, and generally, adopt the multilayer stacking method, with particular direction of overlay and size of each layer, considering about the relationship between layers. In addition, the bronze is used for the Hui-style door decoration. Compared with the iron door, the bronze texture is more exquisite, and with the years increase, it will be shinier by touching. In the craft technique, it also includes the hollowing out and line carving, and the craft is much more delicate, in addition, some complex modeling achieve the effect of embossment by using dies.

Studying its reason, we can know the "Xinan painting" rose in the Ming Dynasty drives the development of Huizhou printing, and it originated from the book engraving, and with the development, naturally extended to other areas, and at the time architectural decoration is also improved with the development of craftsmanship of the worker, but Shanxi is far in its geographical location, so Shanxi gets less benefit than ancient Huizhou.

\section{CONCLUSION}

As an integral part of residential art, Shanxi door decoration directly reflects the aspirations of local people. This article made case analysis and developed a series of thought on the form and connotation of Shanxi door decorations, and then analyzed the significant historical character and regional features under the influence of historical background of the Ming and Qing dynasties and the culture of Shanxi merchants. In the research, we found some related problems and try to solve them. 


\section{REFERENCES}

[1] Tao Siyan: "China town materials ", Orient publishing center, Shanghai, 2012.

[2] Lou Qingxi: "the beauty of thousand doors ", Tsinghua University Press, Beijing, 2011.

[3] Li Qiuxiang, Luo Deyin, Jia Jun: "northern dwellings", Tsinghua University Press, Beijing, 2010.

[4] Wang Jianhua: "Decorative Illustrated Handbook of Sanjin ancient building", Shanghai Literature and Art Publishing House, Shanghai, 2005 .

[5] Li Qiuxiang: “Ding village”, Tsinghua University Press, Tsinghua University Press, Beijing, 2007. 